Article

\title{
Further Validation of the Leisure Time Physical Activity Instrument in People with Chronic Musculoskeletal Pain
}

\author{
Jessica M. Brooks 1,2*, Emre Umucu 3, Daniel Eagle 4, Blaise Morrison 5, Chungyi Chiu 6, \\ Erin Moser ${ }^{7}$, and Fong Chan ${ }^{4}$ \\ Received: $9^{\text {th }}$ May 2018; Accepted: 19 ${ }^{\text {th }}$ May 2018; Published: $6^{\text {th }}$ November 2018
}

\begin{abstract}
The study purpose was to examine the convergent and discriminant validity of the Leisure Time Physical Activity Instrument (LTPAI). This cross-sectional study included 211 adults with chronic pain from U.S. clinics and community networks. Data were collected on the LTPAI and other similar and distinct self-report measures and assessed using multivariate analysis of variance and bivariate correlations. Physical activity levels were higher in action and maintenance stages for physical activity behavior readiness compared to earlier stages of change. Physical activity was also associated with intrinsic motivation for exercise, self-efficacy for exercise, and exercise outcome expectancy. Light-to-moderate physical activity was higher for normal weight groups compared to overweight groups. These results extend the evidence for the validity of the LTPAI. Given the health benefits of incorporating leisure-time physical activity into daily life, it is important to test the applicability of adapted physical activity measurements among persons most in need of physical activity assessments and interventions.
\end{abstract}

Keywords: Exercise assessment; Psychometrics, Fibromyalgia

\section{Introduction}

Chronic pain is a global health priority because of its high prevalence, excessive demands on healthcare systems, considerable economic burdens, and widespread socio-contextual issues (e.g., opioid misuse; Institute of Medicine, 2011). Although persons affected by chronic pain often lead more sedentary lives (Verbunt, Huijnen, \& Köke, 2009; Wallis, Webster, Levinger, \& Taylor, 2013; Washburn, McAuley, Katula, Mihalko, \& Boileau, 1999), starting and maintaining a regular physical activity and exercise routine can reduce the risk for chronic disease and improve health-related quality of life, similar to effects in the general population (Lee et al., 2012; McVinnie, 2013). Regular physical activity has also been shown to reduce depressive symptoms, pain intensity, and painrelated disability in people with chronic pain (Christensen, Bartels, Astrup, \& Bliddal, 2007; Fransen, McConnell, Harmer, Van der Esch, Simic \& Bennell, 2015; Hayden, Van Tulder, Malmivaara, \& Koes, 2005; Lin, McAuley, Macedo, Barnett, Smeets \& Verbunt, 2011; Mannerkorpi \& Iversen, 2003; Natvig, Bruusgaard \& Eriksen, 1998; Rimmer, Riley, Wang, Rauworth, \& Jurkowski, 2004). Self-report assessments of time spent engaging in physical activity are convenient and cost-effective methods for attaining physical activity information, despite the potential for reporting bias. Given the benefits of physical activity and exercise, further validation of a valid and reliable self-report measure for assessing and monitoring exercise schemes recommended to persons with chronic pain is warranted.

In the past, a few self-report physical activity instruments were developed for pain populations (Hooten et al., 2013; Terwee, Bouwmeester, van Elsland, de Vet, \& Dekker, 2011), including the Baecke Physical Activity Questionnaire (Jacob, Baras, Zeev, \& Epstein, 2001) and the General Activity Scale of the Multidimensional Pain Inventory (Johansson \& Lindberg, 1998). Most recently, the Leisure Time Physical Activity Instrument (LTPAI) was developed and adapted for people with 
fibromyalgia to measure lifestyle physical activity and exercise (Mannerkorpi \& Hernelid, 2005). Lifestyle or leisure-time physical activity is defined as leisure, occupational, or household activities that vary in intensity and are planned or unplanned (Dunn, Andersen, \& Jakicic, 1998). Psychometric properties of the LTPAI have been found to be satisfactory in an initial validation study (Mannerkorpi \& Hernelid, 2005) and a subsequent transcultural validation of a Spanish-language version of the instrument (Munguía-Izquierdo, Legaz-Arrese, \& Mannerkorpi, 2011), in which both were performed with populations of adult women with fibromyalgia. A recent study (Segura-Jiménez et al., 2014) found that time spent in physical activity was higher when assessed by the LTPAI when compared with results from an accelerator, albeit this is not unexpected due to the inherent bias of self-report questionnaires.

The purpose of this study was to further examine the psychometric properties of the LTPAI in people with fibromyalgia and other chronic musculoskeletal pain disorders. Convergent validity was examined by comparing self-reported physical activity levels from the LTPAI to the physical activity behavior stages from the well-established psychological readiness measure of Stages of Change Scale for Physical Activity Instrument (Nigg et al., 2005). The association between LTPAI and prominent motivational factors relevant to physical activity, including intrinsic motivation for exercise (Markland \& Tobin, 2004), self-efficacy for exercise (Bandura, 1997), and exercise outcome expectancy (Resnick, Zimmerman, Orwig, Furstenberg, \& Magaziner, 2000), were also examined in the current study. Based on prior research (Chiu, Fitzgerald, Muller, Brooks, \& Chan, 2012; Chiu, Lynch, Berven, \& Chan, 2011; Deci \& Ryan, 2002; Scholz, Keller, \& Perren, 2009), it was hypothesized that the readiness for physical activity and exercise motivation variables would be associated with higher levels of physical activity participation. Discriminant validity was also examined by comparing physical activity levels from the LTPAI to body mass index (BMI). In line with previous studies (Okifuji \& Hare, 2015), it was hypothesized that higher BMI would be associated with reduced physical activity participation. In line with previous studies (Okifuji \& Hare, 2015), it was hypothesized that higher BMI would be associated with reduced physical activity participation

\section{Materials and methods}

\section{Participants and procedures}

Participants were recruited from the following community or clinic networks within the United States: (a) Midwest pain, physical therapy, and primary care churches and clinics; and (b) national chronic pain and fibromyalgia support groups. Inclusion criteria for participation in this study were: (1) diagnosed with nonmalignant, chronic musculoskeletal pain; (2) at least 18 years old; (3) living with pain for longer than 3 months; and (4) able to engage in some type of physical activity. Following institutional review board approval, volunteer collaborators from the above networks were contacted and participants were recruited by advertisements through newsletters, bulletins, and recruitment flyers. Prospective participants were invited to complete an online questionnaire on SurveyMonkey. According to SurveyMonkey's response summary, 253 participants started the survey and 211 participants $(83 \%)$ completed it. It is possible that $17 \%$ of the participants did not finish the survey due to length of the survey. Participants provided informed consent on SurveyMonkey prior to completing the research packet that included demographic questions and standardized measurement tools. Participants had the option to request a $\$ 15$ gift card after completing the online survey; their contact information was automatically transmitted to a file independent from their survey data to ensure confidentiality.

\section{Measures}

\section{Physical activity}

Physical activity was measured using the LTPAI (Mannerkorpi \& Hernelid, 2005). The instructions in the LTPAI ask participants to recall the average number of hours spent engaging in weekly physical activity and exercise during their leisure time over the past month. The LTPAI 
consists of four activity level categories: sedentary, light, moderate, and vigorous. Participants were provided a description of each activity level, and asked to select from the item responses available within one or more activity levels, including: (a) 0.5 to 1.5 hours a week, (b) 2 to 4 hours a week, and (c) more than 4 hours a week. The total score for all activity levels was calculated by using the mean value of the three steps $(1,3$, and 5 hours, respectively). If sedentary or no level was selected for an activity category, the number of hours was assigned a value of 0 for that category. Mannerkorpi and Hernelid (2005) reported a test-retest reliability estimate of .86 for the LTPAI.

\section{Physical activity behavior}

The Physical Activity Stages of Change Instrument (Nigg et al., 2005) was used to measure readiness to engage in physical activity. The scale is comprised of four items (e.g., "Do you currently engage in regular physical activity?"), and the items are rated in a dichotomous "yes" or "no" format. In this study, the item wording was slightly modified to capture both physical activity and exercise. Nigg et al. (2005) provided a scoring algorithm to convert the scores into the four items to represent the degree of engagement in physical activity along a 5-point continuum: 1 (precontemplation [PC]), 2 (contemplation [C]), 3 (preparation [P]), 4 (action [A]), and 5 (maintenance [M]). Nigg et al. (2005) also reported that the model of the scale has significant goodness of fit for the population estimates.

\section{Body mass index (BMI)}

BMI for each participant was calculated from the collected information on sociodemographic characteristics, including height and weight. BMI is calculated by dividing weight in kilograms by height in meters squared.

\section{Intrinsic motivation}

The Behavioral Regulation in Exercise Questionnaire-2 (BREQ-2; Markland \& Tobin, 2004) was used to measure intrinsic motivation for exercise. The BREQ-2 is a 19-item scale based on selfdetermination theory to assess behavioral regulation relevant to exercise. The scale is comprised of five subscales measuring five types of regulation for exercise: amotivation (4 items: e.g., "I do not see why I should have to exercise"), external regulation (4 items: e.g., I exercise because other people say I should"), introjected regulation (3 items: e.g., "I feel guilty when I do not exercise"), identified regulation (4 items: e.g., "I value the benefits of exercise"), and intrinsic regulation (4 items: e.g., "I exercise because it is fun"). In line with contemporary definitions of intrinsic motivation (Ryan \& Deci, 2000), we used both intrinsic regulation and identified regulation subscales to create an "intrinsic motivation scale". The BREQ-2 assesses motivation by using the stem, "Why do you exercise?" Participants respond to each item on a 5-point rating scale ranging from 0 (not true for me) to 4 (very true for me). For this study, the single question and item descriptions were slightly modified to capture engagement in physical activity and exercise. Markland and Tobin (2004) reported the internal consistency estimates of BREQ-2 subscales to range from .73 to .86 .

\section{Exercise self-efficacy}

The Exercise Self-Efficacy Scale (ESES; Bandura, 1997) was used to measure self-efficacy for exercise. The scale is comprised of 18 items with three subscales: (a) situational/interpersonal (e.g., "When I have too much to do at home"), (b) competing demands (e.g., After recovering from an illness that caused me to stop exercising), and (c) internal feelings (e.g., "When I am feeling tired"). Participants provided ratings from $0 \%$ (cannot do) to $100 \%$ (certain can do) on their confidence to perform physical activity and exercise routines regularly (three or more times a week) under various circumstances. Shin, Jang, and Pender (2001) reported the internal reliability estimate to be .94 for the ESES. 


\section{Exercise outcome expectancy}

The 9-item Outcome Expectancies for Exercise (OEE) Scale (Resnick, Zimmerman, Orwig, Furstenberg, \& Magaziner, 2000) was used to measure exercise outcome expectancies. The scale is composed of nine items focusing on the positive expectations of exercise (e.g., "Exercise improves my endurance in performing my daily activities"). Each item is rated on a 5-point Likert-type scale ranging from 0 (not true) to 4 (very true for me), but the rating scale was re-coded for ease of interpretation. Item wording was also modified to indicate physical activity and exercise. Resnick et al. (2000) reported the internal consistency reliability estimate to be .89 for the OEE.

\section{Data Analysis}

The Statistical Package for the Social Sciences (SPSS), Version 24 (IBM Corp., 2016) for Windows was used to perform all data analyses. Means, standard deviations (SDs), and frequencies were used to describe the sample. For convergent and discriminant validity, multivariate analysis of variance (ANOVA) was performed to examine whether physical activity behavior stages and BMI groups differed by the physical activity levels from the LTPAI. Post hoc tests with Bonferroni correction were performed to determine which BMI groups and physical activity behavior stages significantly differed from LTPAI levels. Bivariate correlations between the LTPAI levels and intrinsic motivation for exercise, self-efficacy for exercise, and exercise outcome expectancy scale scores were calculated in order to further evaluate convergent validity. The significance level alpha was established as < 0.05 .

\section{Results}

\section{Study population}

Two hundred and eleven persons with fibromyalgia and/or other chronic musculoskeletal pain disorders volunteered to participate in this study. Participant ages ranged from 18 to 82 years $(\mathrm{M}=$ $43.4, \mathrm{SD}=14.4)$. One hundred and eighty-three participants $(86.7 \%)$ were women and 28 participants $(13.3 \%)$ were men. The majority of the sample described themselves as Caucasian/White $(89.1 \%)$. The median annual household income for participants was $\$ 42,500(\mathrm{M}=\$ 48,425, \mathrm{SD}=\$ 46,455)$, which is considered to be living in a middle-income household in the U.S. Light physical activity and exercise was the most commonly reported type of leisure-time physical activity $(\mathrm{M}=2.35$ hours, $\mathrm{SD}=1.39$ hours). Moderate physical activity and exercise was the second most common leisure-time physical activity ( $\mathrm{M}=1.79$ hours, $\mathrm{SD}=1.26$ hours), and the least common was vigorous physical activity and exercise $(\mathrm{M}=1.25$ hours, $\mathrm{SD}=.95$ hour $)$.

\section{Convergent validity}

A multivariate ANOVA was performed to examine whether physical activity behavior stages differed by the physical activity levels from the LTPAI. The results revealed significant differences across all levels of physical activity behavior stages, including light activity, $\mathrm{F}(4,200)=8.72, \mathrm{p}<.01$; moderate activity, $\mathrm{F}(4,200)=22.13, \mathrm{p}<.01$; and vigorous activity, $\mathrm{F}(4,200)=9.85, \mathrm{p}<.01$. Table 1 demonstrates the means and standard deviations for the physical activity levels by physical activity behavior stages.

Post-hoc comparisons using the Bonferroni procedure indicated that participants in precontemplation (Mean difference $=-1.53, \mathrm{p}<.01$ ), contemplation (Mean difference $=-1.21, \mathrm{p}<.01$ ), and preparation stages (Mean difference $=-0.80, \mathrm{p}<.01$ ) had significantly less time devoted to light physical activity than participants in maintenance stages. Participants in precontemplation (Mean difference $=-1.37, \mathrm{p}<.01$; Mean difference $=-1.75, \mathrm{p}<.01$ ), contemplation (Mean difference $=-1.15, \mathrm{p}$ $<.01$; Mean difference $=-1.53, \mathrm{p}<.01$ ), and preparation stages (Mean difference $=-0.99, \mathrm{p}<.01$; Mean difference $=-1.34, \mathrm{p}<.01$ ) also had significantly less time devoted to moderate physical activity than participants in the action and maintenance stages, respectively. Participants in precontemplation (Mean difference $=-0.93, \mathrm{p}<.01$ ), contemplation (Mean difference $=-0.76, \mathrm{p}<.01$ ), and preparation 
(Mean difference $=-0.79, \mathrm{p}<.01$ ), stages had significantly less time devoted to vigorous physical activity than participants in the maintenance stages.

Table 1. Means and Standard Deviations of Physical Activity Levels of the LTPAI by Physical Activity Behavior Stages from the Physical Activity Stages of Change Instrument

\begin{tabular}{lcccc}
\hline & \multicolumn{3}{c}{ Physical Activity Levels of the LTPAI } \\
\hline & $\mathrm{N}$ & $\begin{array}{c}\text { Light Physical } \\
\text { Activity } \\
\mathrm{M}(S D)\end{array}$ & $\begin{array}{c}\text { Moderate Physical } \\
\text { Activity } \\
\mathrm{M}(S D)\end{array}$ & $\begin{array}{c}\text { Vigorous Physical } \\
\text { Activity } \\
\mathrm{M}(S D)\end{array}$ \\
\hline $\begin{array}{l}\text { Stage of Change } \\
\text { Precontemplation }\end{array}$ & 30 & $1.50(1.17)$ & $0.97(0.67)$ & $0.83(0.38)$ \\
Contemplation & 24 & $1.82(1.33)$ & $1.18(0.59)$ & $1.00(0.00)$ \\
Preparation & 75 & $2.24(1.42)$ & $1.38(0.81)$ & $0.97(0.44)$ \\
Action & 18 & $2.44(1.15)$ & $2.33(1.37)$ & $1.56(1.15)$ \\
Maintenance & 64 & $3.03(1.22)$ & $2.71(1.43)$ & $1.76(1.35)$ \\
Total & 211 & $2.35(1.39)$ & $1.79(1.26)$ & $1.25(0.95)$ \\
\hline
\end{tabular}

Note. The Physical Activity Stage of Change Instrument measures perceived readiness to engage in physical activity behavior along a stage of change continuum: precontemplation, contemplation, preparation, action, and maintenance. The LTPAI measures self-reported, weekly physical activity levels in hours.

All physical activity levels were also significantly associated with the other physical activityrelated psychological constructs. The light physical activity level was significantly associated with intrinsic motivation for exercise $(\mathrm{r}=.39, \mathrm{p}<.01)$, self-efficacy for exercise $(\mathrm{r}=.40, \mathrm{p}<.01)$, and exercise outcome expectancy $(\mathrm{r}=.29, \mathrm{p}<.05)$. The moderate physical activity level was associated with intrinsic motivation for exercise $(\mathrm{r}=.44, \mathrm{p}<.01)$, self-efficacy for exercise $(\mathrm{r}=.46, \mathrm{p}<.01)$, and exercise outcome expectancy $(\mathrm{r}=.33, \mathrm{p}<.05)$. Lastly, the vigorous physical activity level was positively associated with intrinsic motivation for exercise $(\mathrm{r}=.29, \mathrm{p}<.01)$, self-efficacy for exercise $(\mathrm{r}=.37, \mathrm{p}<$ $.01)$, and exercise outcome expectancy $(\mathrm{r}=.18, \mathrm{p}<.05)$.

\section{Discriminant validity}

A multivariate ANOVA was performed to examine whether BMI differed by the physical activity levels from the LTPAI. ANOVA results revealed a significant difference for BMI on light physical activity, $\mathrm{F}(2,200)=4.63, \mathrm{p}<.05$ and moderate physical activity level, $\mathrm{F}(2,200)=4.43, \mathrm{p}<.05$. Table 2 demonstrates the means and standard deviations for the physical activity levels by BMI.

The post-hoc comparisons indicated that participants within the normal weight group (Mean difference $=0.68, \mathrm{p}<.05$ ) had significantly greater amounts of time devoted to light physical activity than obese participants. Participants within normal weight range (Mean difference $=0.59, p<.05$ ) also had greater amounts of time devoted to moderate physical activities than obese participants.

Table 2. Means and Standard Deviations of Physical Activity Levels of the LTPAI by Body Mass Index

\begin{tabular}{lcccc}
\hline & \multicolumn{3}{c}{ Physical Activity Levels of the LTPAI } \\
\hline & $\mathrm{N}$ & $\begin{array}{c}\text { Light Physical } \\
\text { Activity } \\
\mathrm{M}(S D)\end{array}$ & $\begin{array}{c}\text { Moderate Physical } \\
\text { Activity } \\
\mathrm{M}(S D)\end{array}$ & $\begin{array}{c}\text { Vigorous Physical } \\
\text { Activity } \\
\mathrm{M}(S D)\end{array}$ \\
\hline $\begin{array}{l}\text { Body Mass Index } \\
\text { Normal }\end{array}$ & 64 & $2.72(1.46)$ & $2.16(1.32)$ & $1.36(0.95)$ \\
$\quad$ Overweight & 50 & $2.35(1.36)$ & $1.67(1.33)$ & $1.41(1.19)$ \\
Obese & 95 & $2.04(1.27)$ & $1.57(1.13)$ & $1.07(0.76)$ \\
Total & 211 & $2.33(1.38)$ & $1.78(1.26)$ & $1.24(0.95)$ \\
\hline
\end{tabular}

Note. Normal BMI ranges from 18.5-24.9. Overweight groups had a BMI ranging from 25.0-29.9. Obese groups had a BMI at 30.0 or above. The LTPAI measures self-reported, weekly physical activity levels in hours. 


\section{Discussion}

The Leisure Time Physical Activity Instrument (LTPAI) was initially developed for people with fibromyalgia (Mannerkorpi \& Hernelid, 2005). This study provides further evidence for the convergent and discriminant validity of the LTPAI among persons with fibromyalgia and other types of chronic musculoskeletal pain. Convergent validity was supported by comparing the self-reported physical activity levels from the LTPAI to perceived readiness for engaging in physical activity behavior. Findings showed that the mean time devoted to any level of activity was significantly greater for persons within the maintenance and action stages of physical activity behavior compared to persons within the precontemplation, contemplation, and preparation stages. Physical activity levels were also associated with intrinsic motivation for exercise, self-efficacy for exercise, and exercise outcome expectancy. Discriminant validity was indicated through the higher levels of lightto-moderate physical activity among normal weight groups. However, there were no significant differences in vigorous activity levels among the weight groups. These combined results are consistent with the findings of the initial validation and transcultural validation studies (e.g., Mannerkorpi \& Hernelid, 2005; Munguía-Izquierdo et al., 2011), which have also indicated that the LTPAI has satisfactory psychometric validity properties.

Participants from the current study reported low overall levels of leisure-time physical activity, which is similar to past findings in the pain literature (Verbunt, Huijnen, \& Köke, 2009; Wallis, Webster, Levinger, \& Taylor, 2013; Washburn, McAuley, Katula, Mihalko, \& Boileau, 1999). Given that a recent study (Segura-Jiménez et al., 2014) found that time spent in physical activity was higher when assessed by the LTPAI when compared with results from an accelerator, our findings on activity levels might be found to be even lower if re-assessed or compared to objective measures. Physical activity guidelines suggest that all adults should engage in moderate to vigorous intensity for a total of 2.5 hours each week (US Department of Health and Human Services, 2008), which is less than the 2.35 hours of weekly light physical activity or 1.79 hours of weekly moderate physical activity reported by this study's participants. In spite of these low activity levels, health care professionals can assist persons with chronic pain toward making improvements in physical activity levels through adapted exercise and health intervention programs. Health care professionals should also be aware of other types and definitions of physical activity, including leisure-time physical activities that vary in intensity and are planned or unplanned (Dunn et al., 1998). It is essential to assess and monitor progress toward graded physical activity goals with empirically validated instruments such as the LTPAI.

Although there has been a paucity of self-report measures tested for use in clinical practice and research to assess levels of physical activity and exercise among people with chronic pain, several limitations should be taken into consideration while interpreting these results. The study design involved a convenience sample of participants with chronic pain, biasing the representativeness of the sample. For instance, participants who had access to an online survey may be more financially stable and educated, evidenced by the higher median income. The self-reported nature of an online questionnaire may also lead to reporting bias. For example, participants may have answered questions in a manner that aimed to seek a favorable response. Lastly, because the study was conducted in a predominantly Caucasian/White population, we caution generalizing our results to racial/ethnic minorities. The majority of the participants in this study were also female, with male participants notably underrepresented. Future studies may look to expand their sample to include more male participants and those who identify as a racial/ethnic minority.

\section{Perspectives}

This study extends the evidence for the psychometric validity of the LTPAI to persons with various types of chronic musculoskeletal pain disorders. Despite the potential for reporting bias, the LTPAI appears to be a valid self-report instrument, which means it can be effective, efficient, and easy to administer. Given that there are numerous health benefits to incorporating and maintaining leisure-time physical activity and exercise as a part of a daily life routine, it is important to test the 
usefulness and applicability of adapted physical activity measurements among persons with chronic pain and other common and debilitating health conditions.

\section{Author Affiliations:}

1 Dartmouth College, Lebanon, NH, USA; jessica.m.brooks@dartmouth.edu

2 University of North Texas, Denton, TX, USA; jessica.brooks@unt.edu

3 University of Texas at El Paso, El Paso, TX, USA; umucu@utep.edu

4 University of Wisconsin-Madison, Madison, WI, USA; dreagle@wisc.edu and chan@education.wisc.edu

5 University of North Carolina at Chapel Hill, Chapel Hill, NC, USA; blaise morrison@med.unc.edu

6 University of Illinois Urbana-Champaign, Champaign, IL, USA; chiucy@illinois.edu

7 University of Northern Colorado, Greeley, CO, USA; erin.moser@unco.edu

* Correspondence: jessica.brooks@unt.edu; Tel.: +1-940-565-4938

Author Contributions: Conceptualization, J.M.B., E.U., and F.C.; Methodology, F.C., J.M.B., and E.U.; Analysis, F.C., J.M.B., and E.U.; Investigation, J.M.B., E.U., D.E., B.M., C.C., and E.M..; Resources, J.M.B. and E.U..; WritingOriginal Draft Preparation, J.M.B., E.U., D.E., B.M., C.C., and E.M.; Writing-Review \& Editing, J.M.B., E.U., D.E., B.M., C.C., and E.M.; Visualization, J.M.B., E.U., and F.C.; Supervision, J.M.B. and F.C..; Project Administration, J.M.B..; Funding Acquisition, F.C.

Funding: This research was funded by the U.S. Department of Education, National Institute on Disability and Rehabilitation Research (H133B100034; PI Fong Chan) and the National Institute of Mental Health (T32 MH073553-11; PI Stephen Bartels, PhD).

Conflicts of Interest: The authors declare no conflict of interest. The funders had no role in the design of the study; in the collection, analyses, or interpretation of data; in the writing of the manuscript, and in the decision to publish the results.

\section{References}

Bandura, A. (1997). Self-efficacy: The exercise of control. New York, NY: Freeman.

Chiu, C. Y., Fitzgerald, S. D., Strand, D. M., Muller, V., Brooks, J., \& Chan, F. (2012). Motivational and volitional variables associated with stages of change for exercise in multiple sclerosis: A multiple discriminant analysis. Rehabilitation Counseling Bulletin, 56(1), 23-33. doi:10.1177/0034355212439898

Chiu, C. Y., Lynch, R. T., Chan, F., \& Berven, N. L. (2011). The Health Action Process Approach as a motivational model for physical activity self-management for people with multiple sclerosis: A path analysis. Rehabilitation Psychology, 56(3), 171-181. doi:10.1037/a0024583

Christensen, R., Bartels, E. M., Astrup, A., \& Bliddal, H. (2007). Effect of weight reduction in obese patients diagnosed with knee osteoarthritis: A systematic review and meta-analysis. Annals of the Rheumatic Diseases, 66(4), 433-439. doi:10.1136/ard.2006.065904

Deci, E. L., \& Ryan, R. M. (2002). Handbook of self-determination research. Rochester, NY: University Rochester Press.

Dunn, A. L., Andersen, R. E., \& Jakicic, J. M. (1998). Lifestyle physical activity interventions: History, short-and long-term effects, and recommendations. American Journal of Preventive Medicine, 15(4), 398-412. doi:10.1016/S0749-3797(98)00084-1

Fransen, M., McConnell, S., Harmer, A.R., Van der Esch, M., Simic, M., \& Bennell, K.L.

(2015). Exercise for osteoarthritis of the knee: A Cochrane systematic review. British Journal of Sports Medicine, 49(24), 1554-1557. doi:10.1002/14651858.CD004376

Hayden, J. A., Van Tulder, M. W., Malmivaara, A. V., \& Koes, B. W. (2005). Meta-analysis: Exercise therapy for nonspecific low back pain. Annals of Internal Medicine, 142(9), 765-775.

Hooten, W., Timming, R., Belgrade, M., Gaul, J., Goertz, M., Haake, B., . . Saeger, L. (2013). Institute for Clinical Systems Improvement (ICSI) health care guideline: Assessment and management of chronic pain. Retrieved from

https://www.icsi.org/guidelines_more/catalog_guidelines_and_more/catalog_guidelines/catalog_neurol ogical_guidelines/pain/

IBM Corp. (2016). IBM SPSS Statistics for Windows, Version 24.0. Armonk, NY: IBM Corp.

Institute of Medicine. (2011). Relieving pain in America: A blueprint for transforming prevention, care, education, and research. Washington, D.C.: National Academy of Sciences.

Jacob, T., Baras, M., Zeev, A., \& Epstein, L. (2001). Low back pain: Reliability of a set of pain measurement tools. Archives of Physical Medicine and Rehabilitation, 82(6), 735-742. doi:10.1053/apmr.2001.22623 
Johansson, E., \& Lindberg, P. (1998). Subacute and chronic low back pain. Reliability and validity of a Swedish version of the Roland and Morris Disability Questionnaire. Scandinavian Journal of Rehabilitation Medicine, 30(3), 139-143.

Lee, I.-M., Shiroma, E. J., Lobelo, F., Puska, P., Blair, S. N., Katzmarzyk, P. T., \& Lancet Physical Activity Series Working Group. (2012). Effect of physical inactivity on major non-communicable diseases worldwide: An analysis of burden of disease and life expectancy. The Lancet, 380(9838), 219-229.

Lin, C.-W. C., McAuley, J. H., Macedo, L., Barnett, D. C., Smeets, R. J., \& Verbunt, J. A. (2011). Relationship between physical activity and disability in low back pain: A systematic review and meta-analysis. Pain, 152(3), 607-613. doi:10.1016/j.pain.2010.11.034

Mannerkorpi, K., \& Hernelid, C. (2005). Leisure Time Physical Activity Instrument and Physical Activity at Home and Work Instrument. Development, face validity, construct validity and test-retest reliability for subjects with fibromyalgia. Disability and Rehabilitation, 27(12), 695-701. doi:10.1080/09638280400009063

Mannerkorpi, K., \& Iversen, M. D. (2003). Physical exercise in fibromyalgia and related syndromes. Best Practice \& Research Clinical Rheumatology, 17(4), 629-647. doi:10.1016/S1521-6942(03)00038-X

Markland, D., \& Tobin, V. (2004). A modification to the behavioural regulation in exercise questionnaire to include an assessment of amotivation. Journal of Sport and Exercise Psychology, 26(2), 191-196. doi:10.1123/jsep.26.2.191

McVinnie, D. S. (2013). Obesity and pain. British Journal of Pain, 7(4), 163-170. doi:10.1177/2049463713484296

Munguía-Izquierdo, D., Legaz-Arrese, A., \& Mannerkorpi, K. (2011). Transcultural adaptation and psychometric properties of a Spanish-language version of physical activity instruments for patients with fibromyalgia. Archives of Physical Medicine and Rehabilitation, 92(2), 284-294. doi:10.1016/j.apmr.2010.10.019

Natvig, B., Bruusgaard, D., \& Eriksen, W. (1998). Physical leisure activity level and physical fitness among women with fibromyalgia. Scandinavian Journal of Rheumatology, 27(5), 337-341.

Nigg, C., Hellsten, L., Norman, G., Braun, L., Breger, R., Burbank, P., . . Greaney, M. (2005). Physical activity staging distribution: Establishing a heuristic using multiple studies. Annals of Behavioral Medicine, 29(2), 35-45. doi:10.1207/s15324796abm2902s_7

Okifuji, A., \& Hare, B. D. (2015). The association between chronic pain and obesity. Journal of Pain Research, 8 , 399-408. doi:10.2147/JPR.S55598

Resnick, B., Zimmerman, S. I., Orwig, D., Furstenberg, A.-L., \& Magaziner, J. (2000). Outcome expectations for exercise scale: Utility and psychometrics. The Journals of Gerontology Series B: Psychological Sciences and Social Sciences, 55(6), S352-S356. doi:10.1093/geronb/55.6.S352

Rimmer, J. H., Riley, B., Wang, E., Rauworth, A., \& Jurkowski, J. (2004). Physical activity participation among persons with disabilities: Barriers and facilitators. American Journal of Preventive Medicine, 26(5), 419-425. doi:10.1016/j.amepre.2004.02.002

Ryan, R. M., \& Deci, E. L. (2000). Intrinsic and extrinsic motivations: Classic definitions and new directions. Contemporary Educational Psychology, 25(1), 54-67. doi:10.1006/ceps.1999.1020

Scholz, U., Keller, R., \& Perren, S. (2009). Predicting behavioral intentions and physical exercise: A test of the health action process approach at the intrapersonal level. Health Psychology, 28, 702-708. doi:10.1037/a0016088

Segura-Jiménez, V., Álvarez-Gallardo, I. C., Romero-Zurita, A., Camiletti-Moirón, D., Munguía-Izquierdo, D., Carbonell-Baeza, A., \& Ruiz, J. R. (2014). Comparison of physical activity using questionnaires (leisure time physical activity instrument and physical activity at home and work instrument) and accelerometry in fibromyalgia patients: The Al-Ándalus project. Archives of Physical Medicine and Rehabilitation, 95(10), 1903-1911. doi:10.1016/j.apmr.2014.05.015

Shin, Y., Jang, H., \& Pender, N. J. (2001). Psychometric evaluation of the exercise self-efficacy scale among Korean adults with chronic diseases. Research in Nursing \& Health, 24(1), 68-76.

Terwee, C., Bouwmeester, W., van Elsland, S., de Vet, H., \& Dekker, J. (2011). Instruments to assess physical activity in patients with osteoarthritis of the hip or knee: A systematic review of measurement properties. Osteoarthritis and Cartilage, 19(6), 620-633. doi:10.1016/j.joca.2011.01.002

US Department of Health and Human Services. (2008). 2008 Physical activity guidelines for Americans. Retrieved from https://health.gov/paguidelines/pdf/paguide.pdf

Verbunt, J. A., Huijnen, I. P., \& Köke, A. (2009). Assessment of physical activity in daily life in patients with musculoskeletal pain. European Journal of Pain, 13(3), 231-242. doi:10.1016/j.ejpain.2008.04.006

Wallis, J., Webster, K., Levinger, P., \& Taylor, N. (2013). What proportion of people with hip and knee osteoarthritis meet physical activity guidelines? A systematic review and meta-analysis. Osteoarthritis and Cartilage, 21(11), 1648-1659. doi:10.1016/j.joca.2013.08.003 
Washburn, R. A., McAuley, E., Katula, J., Mihalko, S. L., \& Boileau, R. A. (1999). The Physical Activity Scale for the Elderly (PASE): Evidence for validity. Journal of Clinical Epidemiology, 52(7), 643-651. doi:10.1016/S0895-4356(99)00049-9

(C) 2018 by the authors. Submitted for possible open access publication under the terms and conditions of the Creative Commons Attribution (CC BY) license (http://creativecommons.org/licenses/by/4.0/). 